\title{
Ekstraksi limonit dengan metode dua tahap reduksi selektif dan magnetic separation dengan variasi waktu tahan dan suhu rendah
}

\author{
Eko Budiyanto ${ }^{*}$, Lukito Dwi Yuono ${ }^{2}$, Fathan Bahfie ${ }^{3}$, Danang Sulistiyo ${ }^{4}$ \\ ${ }^{1,2,4}$ Prodi Teknik Mesin, Fakultas Teknik, Universitas Muhammadiyah Metro \\ JI. Ki Hajar Dewantara 15 A Kota Metro, Lampung, Indonesia \\ ${ }^{3}$ Balai Penelitian Teknologi Mineral - Lembaga IImu Pengetahuan Indonesia (BPTM-LIPI) \\ Tanjung Bintang \\ JI. Ir. Sutami, Serdang, Tanjung Bintang, Lampung Selatan, Lampung, Indonesia \\ ${ }^{*}$ Corresponding author: ekobudiyantoiyan@gmail.com
}

\begin{abstract}
The use of limonite and saprolite nickel ore with low Ni content as raw material for the manufacture of FeNi metal with a content of > 5\% Ni has not been widely used. This is because to process limonite and saprolite ore into high levels of FeNi concentrate, it requires greater energy. The purpose of this study was to see the beneficiation process of low grade laterite nickel ore (limonite type, with 1-2\% Ni content) at low temperature and holding time with graphite reducing agents and adding additives to iron nickel concentrate and nickel iron concentrates with nickel content above 5\%. The method used in this research is to provide services with temperature variations of $250^{\circ} \mathrm{C}, 300^{\circ} \mathrm{C}$, and $350^{\circ} \mathrm{C}$ with a holding time of 60 minutes and 90 minutes in the heat process stage 1 and continued in the heat process stage 2 , namely at a temperature of $1150^{\circ} \mathrm{C}$ with a holding time of 60 minutes. The concentrates and tailings resulted from magnetic separation were then subjected to XRF testing and optical microscopy. With the erasing process and the holding time, the nickel content was quite high, namely 5-6\%. With this, it can be neglected that the beneficiation process with this method is very effective and optimal. The levels of $F e$ in the concentrate obtained from several tests have increased and decreased with the addition of temperature and holding time.
\end{abstract}

Keywords: Limonite extraction, holding time, low temperature.

\begin{abstract}
Abstrak
Pemanfaatan bijih Nikel limonit dan saprolite dengan kadar Ni yang rendah sebagai bahan baku untuk pembuatan logam FeNi dengan kandungan $>5 \%$ Ni belum banyak dilakukan. $\mathrm{Hal}$ tersebut dikarenakan untuk mengolah bijih limonit dan saprolit menjadi konsentrat $\mathrm{FeNi}$ dengan kadar tinggi dibutuhkan energi yang lebih besar. Tujuan penelitian ini adalah untuk mengetahui proses benefisiasi bijih Nikel laterit kadar rendah (jenis limonit, dengan kandungan $1-2 \% \mathrm{Ni}$ ) pada suhu rendah dan waktu tahan dengan reduktor grafit dan penambahan bahan aditif menjadi konsentrat Iron Nickel serta mengetahui hasil konsentrat Iron Nickel dengan kadar Nikel di atas 5\%. Metode yang digunakan pada penelitian adalah memberikan pemanasan dengan variasi suhu $250^{\circ} \mathrm{C}, 300^{\circ} \mathrm{C}$, dan $350^{\circ} \mathrm{C}$ dengan waktu tahan 60 menit dan 90 menit pada proses panas tahap 1 dan lanjut pada proses panas tahap 2 yaitu pada suhu $1150^{\circ} \mathrm{C}$ dengan waktu 60 menit. Konsentrat dan tailing hasil proses pemisahan magnetik kemudian dilakukan pengujian XRF dan Microskop optik. Dengan dilakukannya proses pemanasan dan waktu penahanan, didapatkan kandungan nikel yang cukup tinggi yaitu 5-6\%. Dengan ini maka dapat disimpulkan bahwa proses benefisiasi dengan metode tersebut sangat efektif dan optimal. Kadar Fe dalam konsetrat yang diperoleh dari beberapa pengujian yaitu mengalami kenaikan dan penurunan dengan ditambahkannya temperatur dan waktu tahan.
\end{abstract}

Kata kunci: Ekstraksi limonit, waktu tahan, suhu rendah. 


\section{Pendahuluan}

Indonesia masih memiliki ketergantungan yang sangat tinggi terhadap baja impor, hal ini disebabkan masih minimnya kapasitas produksi baja Nasional. Saat ini Indonesia masih mengimpor baja sebanyak 6 (enam) juta ton per tahun untuk mencukupi kebutuhan baja dalam negeri [1]. Bijih Nikel laterit merupakan batuan mineral yang mengandung besi, Nikel, khrom, dan cobalt. Batuan mineral tersebut dapat diolah menjadi besi/baja untuk aplikasi baja struktur/konstruksi ataupun baja berkekuatan tinggi. Cadangan bijih besi konvensional di Indonesia memang tidak banyak, namun cadangan bijih Nikel laterit, yaitu lebih dari 1 milyar ton, seharusnya dapat menutupi kebutuhan baja di tanah air. Cadangan bijih Nikel laterit di Indonesia diperkirakan mencapai 1,391 milyar ton (16\% dari cadangan bijih Nikel laterit di dunia) atau menempati urutan kedelapan terbesar di dunia [1]. Gambar 1 memperlihatkan potensi sumber bijih Nikel (a) dan ekspor bijih Nikel (b) Indonesia. Terlihat bahwa Indonesia bersama dengan Filipina menduduki peringkat ke 2 cadangan bijih Nikel terbesar di dunia.

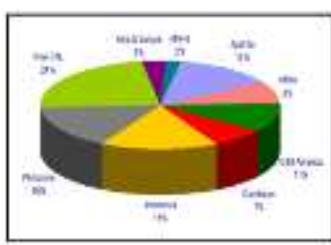

(a)

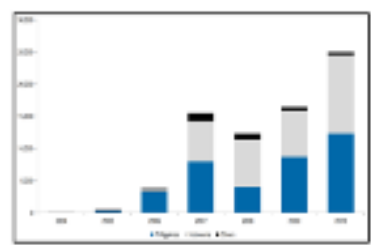

(b)
Gambar 1. Potensi dan ekspor bijih Nikel: (a) potensi bijih Nikel di dunia, (b) ekspor bijih Nikel Indonesia ke China

Kandungan 0,8-3,5\% Nikel dalam bijih Nikel laterit memberikan nilai tambah sehingga batuan tersebut dapat diolah menjadi logam besi/baja yang mengandung Nikel, diantaranya adalah stainless steel, baja berkekuatan tinggi untuk berbagai aplikasi termasuk untuk baja tahan temperatur tinggi. Gambar 2 memperlihatkan secara ilustrasi bagaimana bijih Nikel dari sumbernya setelah pengolahan menjadi produk dengan nilai tambah dalam bentuk aneka produk paduan logam dan baja yang mengandung Nikel bernilai ekonomi tinggi. Guna untuk meningkatkan nilai tambah bijih Nikel dapat dilakukan dengan proses benefisiasi. Benefisiasi adalah proses peningkatan kandungan suatu logam dari bentuk bahan baku hingga menghasilkan konsentrat. Proses benefisiasi sendiri dapat dilakukan dengan tiga cara yaitu magnetic separation, grinding, vibrating screen.
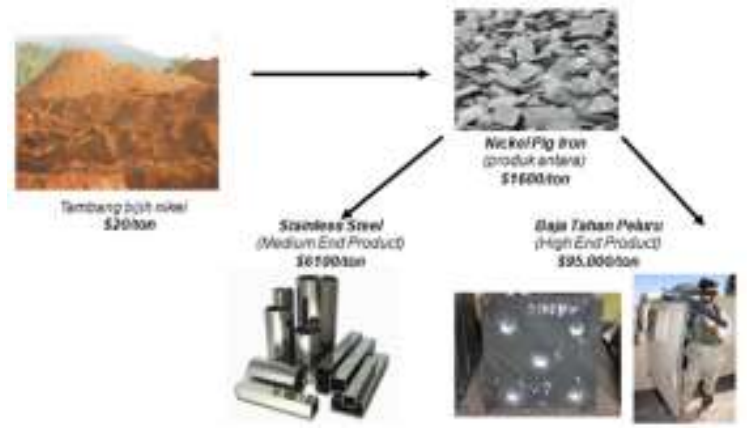

Gambar 2. Peningkatan nilai tambah bijih Nikel laterit menjadi produk akhir

Nikel merupakan salah satu logam paduan dalam material besi dan baja yang mampu memberikan sifat mekanik berupa ketangguhan, ketahanan korosi, dan ketahanan oksidasi pada temperatur tinggi. Untuk proses pengolahan biji Nikel dapat dilakukan dengan proses peleburan dengan temperatur tinggi. Hampir sebanyak $65 \%$ Nikel di dunia digunakan untuk pembuatan material stainless steel, seperti ditunjukkan oleh Gambar 3. Unsur Nikel dalam material stainless steel diperoleh melalui penambahan material electrolytic nickel dan ferronickel (FeNi).

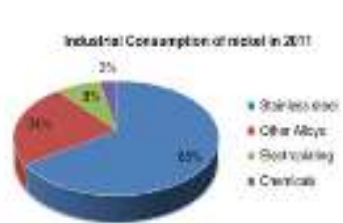

(a)

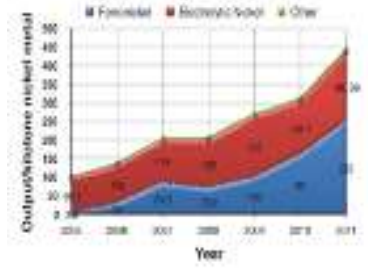

(b)
Gambar 3. Stainless steel dan Nikel: (a) penggunaan logam Nikel di dunia dan (b) produksi stainless steel di dunia

Bijih Nikel laterit dikelompokkan menjadi dua jenis yaitu saprolit $(2-3 \% \mathrm{Ni})$ dan limonit (1-2\% Ni). Teknologi pemanfaatan bijih Nikel laterit jenis saprolit sebagai bahan baku pembuatan electrolytic 
nickel dan ferronickel (FeNi) telah dilakukan di Indonesia, diantaranya oleh PT. Antam dan PT. INCO yang menghasilkan Nikel matte sebesar $70 \%$ Ni. Namun, pemanfaatan bijih Nikel limonit dan saprolite dengan kadar $\mathrm{Ni}$ yang rendah sebagai bahan baku untuk pembuatan logam FeNi dengan kandungan $>5 \%$ Ni belum banyak dilakukan. Hal tersebut dikarenakan untuk mengolah bijih limonit dan saprolit menjadi konsentrat $\mathrm{FeNi}$ dengan kadar tinggi dibutuhkan energi yang lebih besar. Oleh karena itu perlu dipelajari metode yang lebih ekonomis dan tepat dalam pengolahan bijih Nikel limonit dan saprolite menjadi konsentrat $\mathrm{FeNi}$ dengan kandungan $\mathrm{Ni}>5$ $\%$.

\section{Tinjauan Pustaka}

\section{Bijih Nikel}

Nikel merupakan logam yang penting dan mempunyai banyak kegunaan, penggunaan Nikel sangat beragam, baik Nikel primer (produk Nikel yang berasal dari pemrosesan bijih Nikel) maupun Nikel sekunder (produk Nikel yang berasal dari pemrosesan Nikel primer). Sebanyak $48 \%$ Nikel primer digunakan untuk produksi baja tahan karat (stainless steel) dan baja paduan, $39 \%$ digunakan untuk produksi paduan non logam (nonferrous alloy) dan superalloy dan $10 \%$ untuk elektroplating. Sedangkan untuk Nikel sekunder, 30\% digunakan untuk transportasi, $14 \%$ digunakan untuk produksi produk-produk metal, $12 \%$ untuk peralatan elektronik, $10 \%$ digunakan pada industri petroleum, dan sisanya $8 \%$ digunakan pada industri kimia, konstruksi, peralatan rumah tangga dan industri mesin [2]. Nikel laterit merupakan salah satu sumber Nikel yang tersimpan dalam bentuk batuan, memiliki kadar Nikel lebih rendah dibandingkan dengan Nikel Sulfida. Nikel dalam bijih laterit tercampuri dengan besi oksida dan mineral silikat sebagai hasil substitusi isomorphous unsur besi dan magnesium dalam unsur kristalnya [3]. Jumlah simpanan Nikel laterit di dunia sekitar $72 \%$ sedangkan sisanya merupakan simpanan Nikel Sulfida. Meskipun Nikel laterit memiliki porsi yang lebih tinggi dibandingkan dengan deposit Nikel Sulfida dapat dilihat secara grafik pada Gambar 4, namun dalam pemanfaatannya, Nikel Sulfida lebih banyak diolah dan dimanfaatkan karena kandungan Nikelnya yang lebih tinggi dibandingkan dengan Nikel laterit [4].

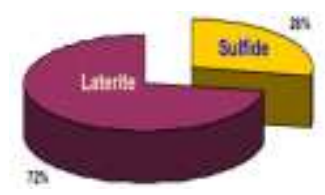

(a)

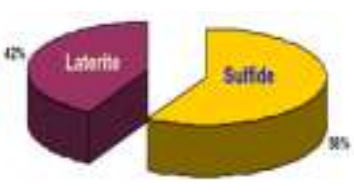

(b)
Gambar 4. Data Cadangan Nikel dan Produksi Nikel di Dunia, (a) cadangan, (b) produksi [4]

Secara kimiawi zona limonit umumnya terdiri atas unsur-unsur yang tidak mudah larut (residual) seperti $\mathrm{Fe}, \mathrm{Al}$, $\mathrm{Cr}, \mathrm{Ti}, \mathrm{Mn}$ dan Co, akan tetapi dalam hal ini unsur yang paling sering dipakai adalah Fe karena biasanya berasosiasi dengan mineral utama yang dijumpai pada zona limonit. Pada zona limonit unsur Mg dijumpai dalam jumlah kecil karena $\mathrm{Mg}$ biasanya berasosiasi dengan mineral olivine, piroksen dan serpentin yang tidak dijumpai di zona ini, sedangkan unsur $\mathrm{Ni}$ biasanya dijumpai dalam jumlah yang tidak terlalu tinggi.

\section{Jenis-Jenis Bijih Nikel}

Bijih Nikel Sulfida terbentuk melalui proses vulkanik atau hidrotermal, banyak mengandung tembaga dan kobalt, sedikit logam mulia seperti emas, platinum, palladium dan rhodium, biasanya mengandung $0,4-2 \% \mathrm{Ni}, 0,2-2 \% \mathrm{Cu}, 10$ $30 \%$ Fe dan 20\% S. Bijih Nikel Sulfida merupakan campuran dari mineral Sulfida dengan berbagai mineral batuan [5]. Laterit dihasilkan dari pelapukan batuan secara kimiawi yang berlangsung dalam waktu yang panjang dibawah suhu yang cukup tinggi pada kondisi iklim basah atau lembab. Nikel laterit adalah hasil laterisasi batuan ultramafik yang memiliki kandungan besi dan magnesium yang tinggi, dapat ditemukan pada tanah yang relatif dangkal yaitu sekitar 6-15 m, tetapi bisa juga mencapai 60 meter. Pembentukan bijih Nikel laterit dapat berlangsung lebih dari 
satu juta tahun [6]. Pada Gambar 5 diperlihatkan foto wujud fisik dari laterit.

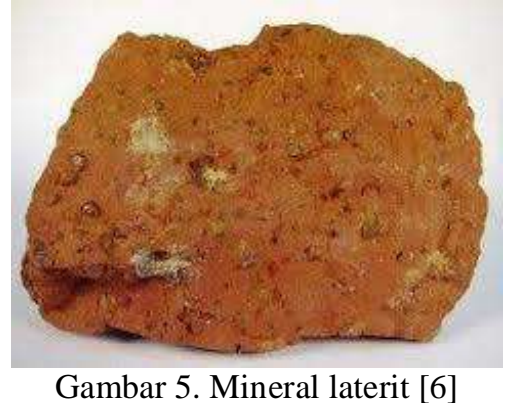

Bijih laterit limonit diperkaya oleh zat besi, namun mengandung silika dan magnesium yang rendah (Fe $15-32 \%, \mathrm{MgO}$ $<10 \%$ ). Komponen utama dari bijih laterit limonit adalah oksida besi, kobalt dan kromium [6]. Bijih laterit saprolit mengandung zat besi yang lebih rendah dengan magnesium yang lebih tinggi ( $\mathrm{Fe}<$ $12 \%$ dan $\mathrm{MgO}>25 \%$ ) seperti pada Gambar 6. Bijih laterit saprolit disebut sebagai garnierite [5].

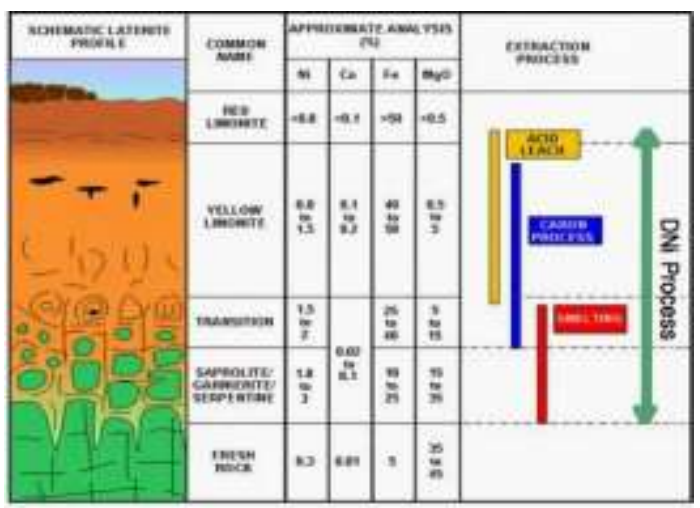

Gambar 6. Susunan bijih laterit [5]

\section{Proses Pengolahan Bijih Laterit Menjadi Nikel}

Laterit dapat diproses untuk menghasilkan Nikel dengan dua cara, yaitu dengan hidrometalurgi dan pirometalurgi. Hidrometalurgi merupakan proses pemurnian logam dengan menggunakan pelarut kimia untuk melarutkan bahan logam tertentu sehingga kemurnian logam yang diinginkan meningkat (leaching).

Hidrometalurgi merupakan metode yang cukup menjanjikan karena mampu menghasilkan Nikel dengan kemurnian tinggi. Selain itu, pelarut dapat di daur ulang dan digunakan kembali sehingga dapat mengurangi biaya produksi. Akan tetapi pada proses ini masih meninggalkan residu dari pelarut kimia tersebut yang dapat membahayakan lingkungan dan kesehatan. Selain itu, pengolahan melalui pirometalurgi yaitu smelting merupakan teknologi yang sudah sangat banyak digunakan untuk memproduksi ferro nickel atau nickel matte. Proses ini cocok untuk mengolah bijih saprolite/limonit dengan kadar $\mathrm{Ni}$ yang tinggi (>2\%), $\mathrm{Mg}$ yang tinggi (10\%-15\%) dan Fe yang rendah (13-20\%).

Dalam pembuatan ferronickel, bijih dicampur dengan batubara kemudian dikeringkan dan dikalsinasi dalam tanur putar pada suhu $900^{\circ} \mathrm{C}-1000^{\circ} \mathrm{C}$. Hasil kalsinasi kemudian di-smelting dan ditambahkan kembali batubara ke dalam electric furnace pada suhu $1550^{\circ} \mathrm{C}$. Hasilnya berupa $\mathrm{Ni}$ dan $\mathrm{Fe}$ yang sudah tereduksi sempurna 60\%-70\%. Fe, $\mathrm{Mg}$, dan $\mathrm{SiO}_{2}$ yang tersisa akan tertinggal dalam campuran slag [7].

Hanya sekitar $40 \%$ industri-industri yang ada didunia memproduksi bijin Nikel laterit dengan menggunakan proses smelting [5]. Dan untuk menghilangkan moisture yang terdapat dalam bijih Nikel dengan proses pengeringan sehingga kelembaban dari Nikel laterit berkisar antara 30-45\% akan berkurang. Proses ini biasanya berlangsung pada temperatur $100-200{ }^{\circ} \mathrm{C}$ [8].

\section{Jenis Teknik Inovasi Upgrading}

Proses prekonsentrasi secara pirometalurgi atau lebih umum dikenal sebagai upgrading process dilakukan untuk memperoleh Nikel dan atau feroNikel dari bijih Nikel laterit, seperti roasting dan smelting. Beberapa jenis teknik inovasi yang terkait dengan proses ini antara lain thermal upgrading process, Sulfidasi selektif dan proses segregasi.

Pemanasan dua tahap adalah teknik yang ditujukan untuk memperlakukan bijih Nikel kadar rendah agar supaya lebih memberikan nilai lebih ketika dilakukan proses benefisiasi fisik. Teknik ini mengacu pada adanya proses reduksi dari Nikel dan kobalt yang terkandung dalam bijih limonit 
untuk menjadi logam yang dapat dipisahkan dari mineral-mineral pengganggu.

Berbagai kondisi operasi seperti temperatur, waktu tahan, suasana reduksi, dan penambahan reagen/bahan aditif bertujuan untuk meningkatkan pertumbuhan ukuran partikel logam yang menguntungkan jika dilakukan pemisahan secara magnetik atau flotasi. Inovasi lain dalam kaitannya dengan thermal upgrading telah dilakukan dimana bijih yang digunakan berupa Nikel kadar rendah yang dicampur dengan $6 \%$ batubara dan $4 \%$ sulfur dan menerapkan metode dua tahap thermal upgrading dan di akhiri dengan pemisahan magnet [9].

Tujuan dari metode dua tahap thermal upgrading adalah untuk men-treatment bijih Nikel kadar rendah agar didapatkan feroNikel yang memiliki kadar dan perolehan kembali logam Nikel yang tinggi dengan penggunaan panas yang tidak terlalu tinggi $\left(\leq 1000^{\circ} \mathrm{C}\right)$ dan penambahan sulfur yang relatif sedikit $(\leq 10 \%)$. Tahap pertama pemanasan dilakukan pada bijih yang dicampur batubara dan sulfur di temperatur $600^{\circ} \mathrm{C}$ selama satu jam untuk mereduksi Nikel oksida dengan sempurna dan mendapatkan fasa Fe-Ni-S yang kaya Nikel.

Hal ini didukung oleh penelitian yang menyatakan bahwa pada kondisi standar dengan tekanan atmosfir, temperatur minimum untuk terjadinya reduksi Nikel oksida dengan pereduksi karbon adalah $440^{\circ} \mathrm{C}$, dan optimal pada temperatur $600^{\circ} \mathrm{C}$.

Tahap kedua atau disebut pemanasan lanjut dilakukan dengan melakukan treatment panas pada temperatur $1000^{\circ} \mathrm{C}$ dan ditahan satu jam untuk membentuk fasa Fe-Ni-S semi-liquid yang mempermudah berkumpulnya partikel feroNikel, selain itu dalam proses pemanasan lanjut juga terjadi pertumbuhan partikel feroNikel. Sesuai dengan penelitian Yang dkk (2016) menyatakan bahwa pengaruh dua tahap pada laterit melalui pengujian DTA pada Gambar 7 [10].

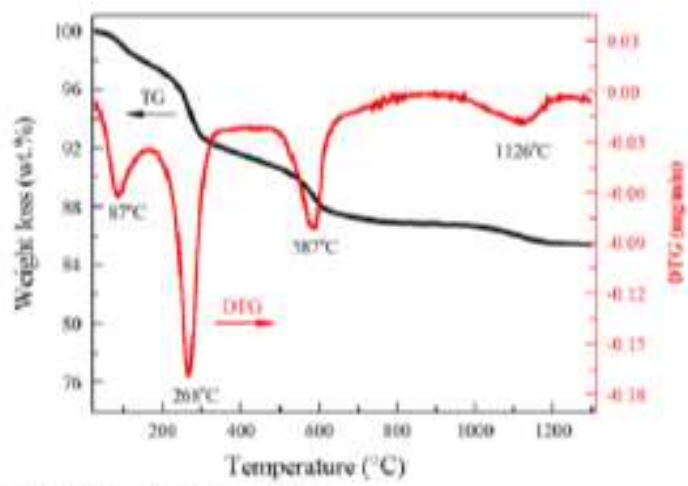

(a)

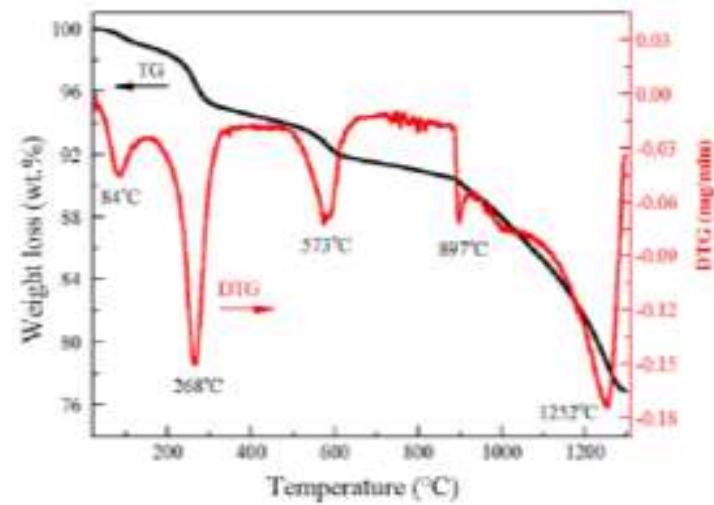

(b)

Gambar 7. Diagram differential thermal analysis (a) tanpa $\mathrm{Na}_{2} \mathrm{SO}_{4}$ dan (b) dengan $\mathrm{Na}_{2} \mathrm{SO}_{4}$

Berdasarkan hasil DTA tersebut bahwa diperlukan adanya tahap pertama untuk menjadikan struktur -OH menjadi oksida sehingga dapat meningkatkan laju difusi Nikel pada besi dan akan mengurangi pembentukan metal besi.

Selain itu, focus penelitian ini untuk memodifikasi dari Paten No. 4.490.174 pada Tabel 1 yaitu dengan melakukan thermal upgrading melalui mekanisme reduksi selektif dua tahap pemanasan menggunakan reduktor grafit, bahan aditif yang ditambahkan berupa $\mathrm{Na}_{2} \mathrm{SO}_{4}$, serta waktu tahan yang lebih singkat $(30,60$, dan 90 menit) dengan variasi temperatur $450{ }^{\circ} \mathrm{C}$, $500{ }^{\circ} \mathrm{C}$, dan $550{ }^{\circ} \mathrm{C}$. Dan dilanjutkan dengan reduksi pada temperatur $1150{ }^{\circ} \mathrm{C}$ selama 60 menit. 
Tabel 1. Paten Thermal Upgrading [11]

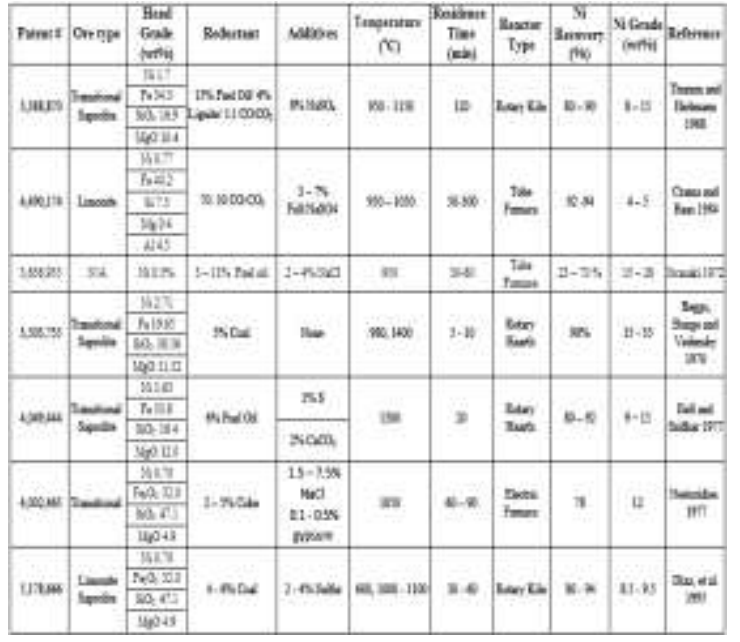

5. Reduksi Temperatur Rendah diikuti Pemisahan Magnetik

Melihat beberapa proses pengolahan bijih Nikel laterit yang dijelaskan di atas, masih perlu dilakukan pengembangan untuk meminimalkan masalah terkait dengan proses seperti yang terjadi pada pirometalurgi dimanamembutuhkan energi yang tinggi sehingga kurang efisien, menghasilkan polusi udara dan pada hidrometalurgi yang manfaat ekonominya rendah serta limbah beracunnya dapat menyebabkan polusi serius.

Penelitian mengenai reduksi selektif pemisahan magnetik Nikel laterit untuk menghasilkan FeroNikel terus berkembang dan fokus pada temperatur rendah. Proses ini dapat digunakan sebagai metode alternatif untuk memproses bijih Nikel kadar rendah. Pemisahan magnetik akan berjalan secara efektif jika terjadi pertumbuhan partikel feroNikel dengan ukuran yang besar. Isu utama proses reduksi selektif pada temperatur rendah yaitu mengurangi reduksi besi oksida. Meskipun membantu Nikel membentuk FeroNikel tetapi tetap saja metalisasi besi harus dibatasi [12].

Pemisahan magnetik adalah teknik pemisahan mineral berdasarkan pada perbedaan sifat magnetiknya. Metode ini digunakan untuk memisahkan mineral berharga dari mineral pengganggu. Terdapat dua jenis pemisahan magnetik, yaitu metode kering dan basah. Metode kering digunakan untuk bahan kasar dan kuat, sedangkan metode basah untuk bahan magnet kuat dalam campuran tanah halus dengan medium air [13]. Bijih laterit dikalsinasi kemudian dilanjutkan dengan pemisahan magnetik metode basah untuk memperoleh Nikel. Metode ini dipilih karena sederhana, hemat biaya, dan ramah lingkungan.

\section{X-Ray Fluorescence (XRF)}

Analisis menggunakan XRF dilakukan berdasarkan identifikasi dan pencacahan karakteristik sinar-X yang terjadi dari peristiwa efek fotolistrik. Efek fotolistrik terjadi karena electron dalam atom target (sampel) terkena berkasberenergi tinggi (radiasi gamma, sinar-X) dari pada energi ikat elektron dalam orbit $\mathrm{K}$, $\mathrm{L}$, atau $\mathrm{M}$ atom target, maka electron atom target akan keluar dari orbitnya. Dengan demikian atom target akan mengalami kekosongan elektron, dapat diisi oleh elektron dari orbital yang lebih luar diikuti pelepasan energi yang berupa sinar$X$. Sinar-X yang dihasilkan merupakan gabungan spektrum sinambung dan spektrum berenergi tertentu (discreet) yang berasal bahan sasaran yang tertumbuk elektron.

Jenis spektrum diskrit yang terjadi tergantung pada perpindahan elektron yang terjadi dalam atom bahan. Spektrum ini dikenal dengan spektrum sinar-X karakteristik. Spektrometri XRF memanfaatkan sinar-X yang dipancarkan oleh bahan yang selanjutnya ditangkap detektor untuk dianalisis kandungan unsur dalam bahan. Bahan yang dianalisis dapat berupa padat massif, pelet, maupun serbuk.

Analisis unsur dilakukan secara kualitatif maupun kuantitatif. Analisis kualitatif menganalisis jenis unsur yang terkandung dalam bahan dan analisis kuantitatif dilakukan untuk menentukan konsetrasi unsur dalam bahan. Sinar-X yang dihasilkan dari peristiwa seperti peristiwa tersebut diatas ditangkap oleh detektor semi konduktor Silikon Litium (SiLi) [14]. 


\section{Microskop Optik (OM)}

Mikroskop Optik adalah instrumentasi optik yang menggunakan cahaya tampak untuk menghasilkan gambar yang diperbesar dari suatu objek (atau spesimen) dan diproyeksikan ke retina mata atau ke perangkat pencitraan. Perbesaran akhir gambar yaitu:

$$
\mathrm{M}_{\mathrm{akhir}}=\mathrm{M}_{\text {objektif }} \times \mathrm{M}_{\text {okuler }}
$$

Dua komponen utama mikroskop dalam bentuk gambar: (1) lensa objektif, yang mengumpulkan cahaya yang teridentifikasi oleh spesimen dan membentuk gambar nyata di dekat okuler dan (2) lensa kondensor, yang memfokuskan cahaya dari iluminator ke area kecil spesimen (gambar nyata dapat dilihat di layar,atau ditampilkan di layar, sementara gambar maya tidak bisa). Spesimen diamati menggunakan lensa objektif yang menghasilkan perbesaran gambar nyata dari objek di bidang gambar okuler. Okuler yang bekerja bersama kornea mata memproyeksikan gambar nyata kedua ke retina dan ditafsirkan oleh otak sebagai perbesaran gambar maya sekitar $25 \mathrm{~cm}$ di depan mata [15].

\section{Metode Penelitian}

Proses reduksi parsial ditujukan untuk mengurangi sebagian senyawa oksida besi yang terkandung dalam bijih Nikel laterit berdasarkan sifat magnetik dari senyawa tersebut. Proses reduksi diawali dengan menghilangkan senyawa hidroksida dengan suhu rendah dan mengoptimalkan pembentukan Nikel pada hasil reduksi bijih laterit serta dipisahkan dengan proses magnet separasi.

Dari proses magnetic separation tersebut akan diperoleh konsentrat yang kaya akan kandungan senyawa oksida Nikel dan memiliki kandungan besi oksida yang lebih sedikit. Proses reduksi yang akan dilakukan dalam penelitian ini laterit, grafit, dan $\mathrm{Na}_{2} \mathrm{SO}_{4}$ dicampurkan pada kondisi ukuran partikelnya 100 mesh lalu suhu rendah tahap pertama dan waktu tahan divariasikan dengan kondisi stoikiometri grafit dan konsentrasi $\mathrm{Na}_{2} \mathrm{SO}_{4}$ yang optimal serta direduksi pada suhu $1150^{\circ} \mathrm{C}$ selama 1 jam tahap kedua. Dalam penelitian ini dipelajari variasi temperatur pada dua tahap proses panas melalui reduksi selektif terhadap bijih Nikel laterit jenis limonit untuk mendapatkan optimal waktu tahan dan temperatur pre-treatment serta menghasilkan konsentrat dengan kadar Nikel di atas 5\%.

Proses pertama mempersiapkan bahan biji Nikel limonit dan bahan reduktor grafit, lalu kemudian masing-masing bahan tersebut diayak dengan menggunakan ayakan -100 mesh. Lalu masuk proses pencampuran bahan yaitu bijih limonit dicampur dengan reduktor grafit dan zat aditif $\mathrm{Na}_{2} \mathrm{SO}_{4}$ setelah pencampuran dilakukan pelletizing yaitu proses pembulatan bahan menjadi seperti bola-bola kecil, kemudian masuk proses pengeringan dengan temperatur $100^{\circ} \mathrm{C}$ selama 1 jam setelah pengeringan selesai masuk pada proses panas tahap 1 yaitu dengan variasi suhu $250^{\circ} \mathrm{C}, 300^{\circ} \mathrm{C}$, dan $350^{\circ} \mathrm{C}$ dengan waktu 60 menit dan 90 menit dan lanjut pada proses panas tahap 2 yaitu pada suhu $1150^{\circ} \mathrm{C}$ dengan waktu 60 menit.

Setelah proses panas selesai langsung dilakukan proses pendinginan cepat menggunakan air lalu dikeringkan lagi dengan suhu $100^{\circ} \mathrm{C}$ selama 4 jam untuk menghilangkan kadar air, setelah bahan benar-benar kering dilakukan penggerusan dan kemudian diayak menggunakan mesh 200 agar bias dilakukan proses pemisahan magnetik, dan lanjut proses pemisahan magnetik dengan metode basah/menggunakan air.

Dari proses ini didapatkan hasil konsentrat dan tailing untuk dilakukan pengujuan XRF dan Microskop optik. Setelah didapat data hasil pengujian tersebut kemudian dilakukan analisa hasil dan kemudian selesai. 


\section{Hasil dan Pembahasan}

\section{Presentase Berat dan Recovery Nikel dan Besi}

Tabel 2. Pengaruh temperatur reduksi pada konsentrat limonit dengan pada waktu reduksi 60 menit terhadap kadar $\mathrm{Fe}$ dan $\mathrm{Ni}$ dengan metode XRF.

\begin{tabular}{cccc}
\hline No & $\begin{array}{c}\text { Suhu } \\
\left({ }^{\circ} \mathrm{C}\right)\end{array}$ & $\begin{array}{c}\text { Kadar Fe } \\
(\% \text { berat })\end{array}$ & $\begin{array}{c}\text { Kadar Ni } \\
(\% \text { berat })\end{array}$ \\
\hline 1 & 250 & 67,853 & 6,079 \\
\hline 2 & 300 & 61,313 & 2,072 \\
\hline 3 & 350 & 63,313 & 2,343 \\
\hline
\end{tabular}

Pada Tabel 2 menunjukkan bahwa kadar Fe dalam konsetrat yang diperoleh yaitu terjadi fluktuasi/naik turun, pada suhu $250^{\circ} \mathrm{C}$ kadar Fe lebih tinggi dan pada suhu $300^{\circ} \mathrm{C}$ kadar Fe semakin menurun kemudian kembali meningkat pada suhu $350{ }^{\circ} \mathrm{C}$. Hal ini pun terjadi sama pada kadar $\mathrm{Ni}$ yang dihasilkan, dimana pada temperatur $250^{\circ} \mathrm{C}$ kadar mencapai $6,079 \%$ dan terjadi penurunan kadar nikel pada suhu $300{ }^{\circ} \mathrm{C}$ menjadi $2,072 \%$, kemudian pada temperatur $350^{\circ} \mathrm{C}$ kembali mengalami kenaikan kadar nikel menjadi $2,347 \%$. Kenapa terjadi kenaikan dan penurunan kadar $\mathrm{Ni}$ pada pengujian ini bisa disebabkan oleh dua faktor yaitu yang pertama faktor waktu dan yang kedua faktor temperatur. Jadi pengujian yang paling optimal yaitu dapat dilihat dari kadar Nikel di atas 5\% atau yang paling besar.

Tabel 3. Pengaruh temperatur reduksi pada konsentrat limonit dengan pada waktu reduksi 90 menit terhadap kadar $\mathrm{Fe}$ dan $\mathrm{Ni}$ dengan metode XRF.

\begin{tabular}{cccc}
\hline No & $\begin{array}{c}\text { SUHU } \\
(\mathrm{oC})\end{array}$ & $\begin{array}{c}\text { Kadar Fe } \\
(\% \text { berat })\end{array}$ & $\begin{array}{c}\text { Kadar } \\
\mathrm{Ni} \\
(\% \\
\text { berat })\end{array}$ \\
\hline 1 & 250 & 64,319 & 5,728 \\
\hline 2 & 300 & 66,013 & 2,820 \\
\hline 3 & 350 & 61,953 & 3,836 \\
\hline
\end{tabular}

Pada Tabel 3 menunjukkan bahwa terjadi kenaikan dan penurunan kadar Fe dan Ni kenaikan kadar Fe terjadi pada suhu 300 ${ }^{\circ} \mathrm{C}$ dan kembali mengalami penurunan pada suhu $350{ }^{\circ} \mathrm{C}$. Hal ini berbanding terbalik dengan kadar Ni pada suhu $300^{\circ} \mathrm{C}$ kadar $\mathrm{Ni}$ mengalami penurunan dan kembali mengalami kenaikan yaitu pada suhu 350 ${ }^{\circ} \mathrm{C}$. \%. Jadi pengujian yang paling optimal yaitu dapat dilihat dari kadar Nikel diatas $5 \%$ atau yang paling besar.

\section{Pengaruh Batas Butir dan Penyebaran} Ferronikel

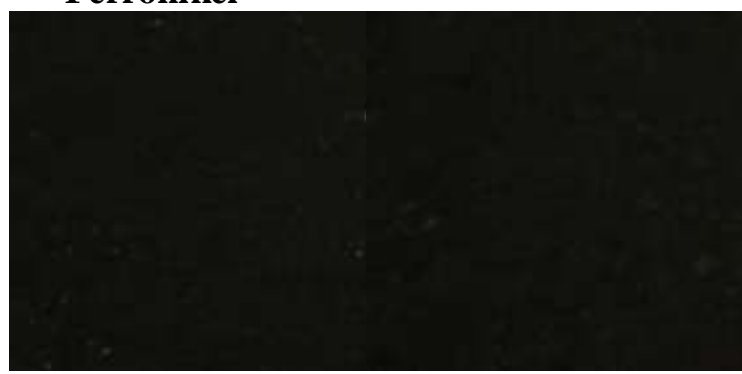

(a)

(b)

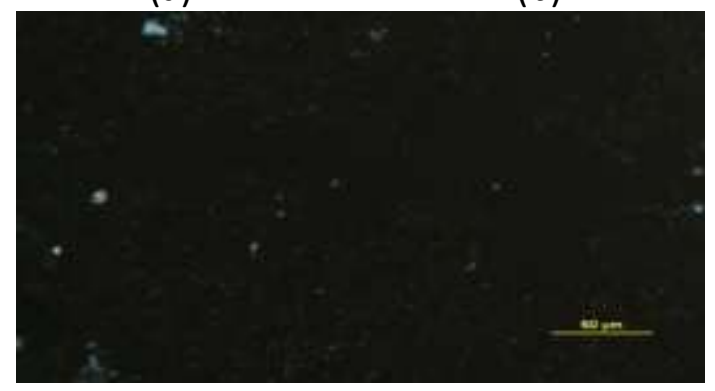

(c)

Gambar 8. Struktur mikro pengaruh temperatur rendah (a) $250^{\circ} \mathrm{C}$, (b) $300^{\circ} \mathrm{C}$, dan (c) $350^{\circ} \mathrm{C}$ dengan konsentrat limonit pada waktu reduksi 60 menit.

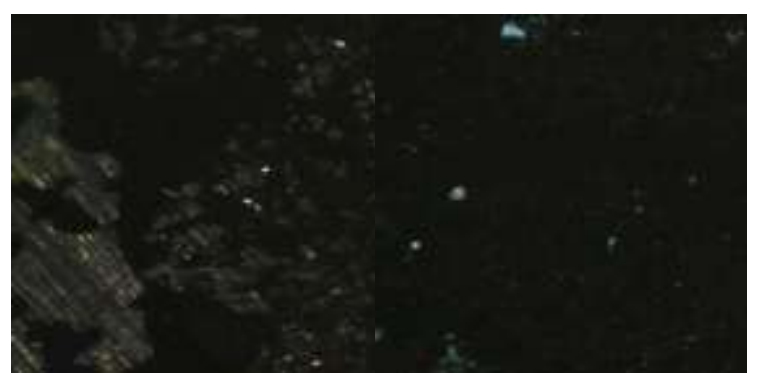

(a)

(b)

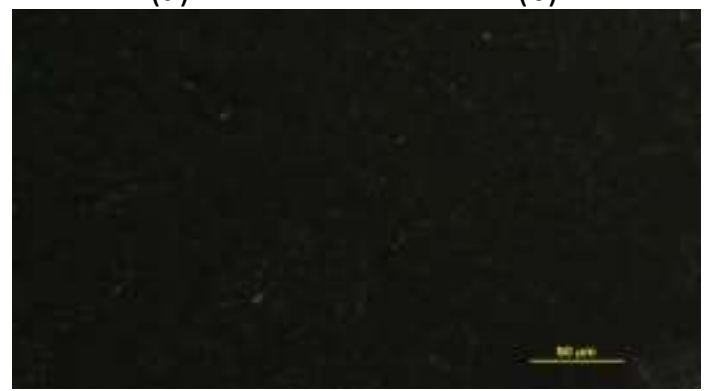

(c)

Gambar 9. Struktur mikro pengaruh temperatur rendah (a) $250^{\circ} \mathrm{C}$, (b) $300^{\circ} \mathrm{C}$, dan (c) $350^{\circ} \mathrm{C}$ dengan konsentrat limonit pada waktu reduksi 90 menit. 
Pada Gambar 8 dan 9 menunjukkan hasil mikrostruktur yang diketahui bahwa butiran terang diidentifikasikan merupakan butir dari logam atau fasa feronikel yang terbentuk. Sementara butir gelap diidentifikasi sebagai fasa lain yang dianggap pengotor. Untuk mengetahui mikrostruktur yang terbentuk pada hasil reduksi, dilakukan pengamatan menggunakan mikroskop optik.

\section{Pembahasan}

Bahan baku yang digunakan pada penelitian ini adalah bijih nikel laterit jenis limonit dari daerah Torobulu Sulawesi Tenggara. Bijih tersebut karakterisasi dengan XRF dan mikroskop optik untuk megetahui komposisi unsur dan struktur mikronya. Optimasi pada proses ini dengan variasi untuk suhu rendah yaitu 250, 300, dan $350{ }^{\circ} \mathrm{C}$ selama 60 menit dan 90 menit pada kondisi suhu reduksi $1150^{\circ} \mathrm{C}$ selama 1 jam dan pada kondisi stoikiometri 0,125 dan konsentrasi $10 \% \mathrm{Na}_{2} \mathrm{SO}_{4}$ yang berpengaruh terhadap persentase berat dan recovery nikel dan besi, fase-fase yang terbentuk, besaran batas butir, dan penyebaran ferronikel.

Pada Tabel 2 menunjukkan bahwa kadar Fe dalam konsetrat yang diperoleh yaitu terjadi fluktuasi/naik turun, pada suhu $250{ }^{\circ} \mathrm{C}$ kadar Fe lebih tinggi dan pada suhu $300^{\circ} \mathrm{C}$ kadar Fe semakin menurun kemudian kembali meningkat pada suhu $350{ }^{\circ} \mathrm{C}$. Hal ini pun terjadi sama pada kadar $\mathrm{Ni}$ yang dihasilkan, dimana pada temperatur $250^{\circ} \mathrm{C}$ kadar mencapai $6,079 \%$ dan terjadi penurunan kadar nikel pada suhu $300{ }^{\circ} \mathrm{C}$ menjadi $2,072 \%$, kemudian pada temperatur $350^{\circ} \mathrm{C}$ kembali mengalami kenaikan kadar nikel menjadi 2,347\%. Dengan ditambahkanya suhu dapat membuat kadar FeNi menurun. Jadi pengujian yang paling optimal yaitu dapat dilihat dari kadar Nikel diatas $5 \%$ atau yang paling besar.

Begitupun pada Tabel 3 menunjukkan bahwa terjadi kenaikan dan penurunan kadar $\mathrm{Fe}$ dan Ni kenaikan kadar Fe terjadi pada suhu $300 \quad{ }^{\circ} \mathrm{C}$ dan kembali mengalami penurunan pada suhu $350{ }^{\circ} \mathrm{C}$. Hal ini berbanding terbalik dengan kadar $\mathrm{Ni}$ pada suhu $300^{\circ} \mathrm{C}$ kadar $\mathrm{Ni}$ mengalami penurunan dan kembali mengalami kenaikan yaitu pada suhu $350{ }^{\circ} \mathrm{C}$. \% . Jadi pengujian yang paling optimal yaitu dapat dilihat dari kadar Nikel di atas $5 \%$ atau yang paling besar.

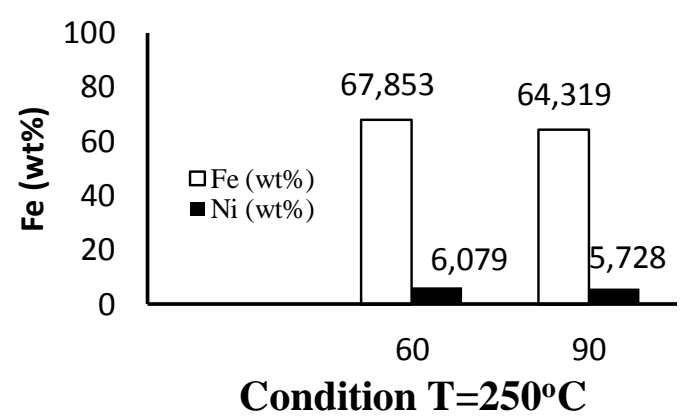

Gambar 10. Kadar Fe dan Ni pada kondisi $\mathrm{T}=250^{\circ} \mathrm{C}$

Pada grafik kondisi suhu $250^{\circ} \mathrm{C}$ kadar $\mathrm{Fe}$ dan $\mathrm{Ni}$ mengalami penurunan seiring ditambahkanya waktu tahan 60 menit menjadi 90 menit. Dapat disimpulkan pada kondisi suhu $250^{\circ} \mathrm{C}$ waktu sangat berpengaruh terhadap nilai kadar FeNi.

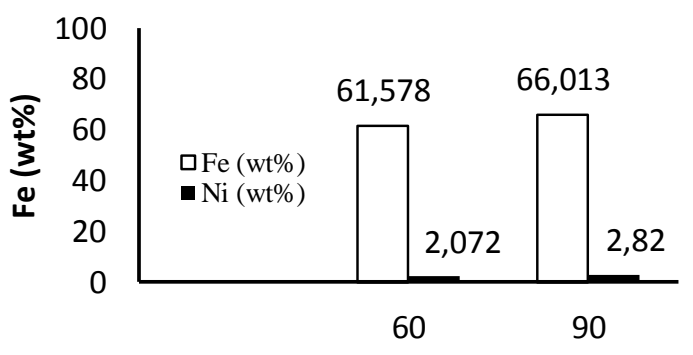

Condition $\mathrm{T}=300^{\circ} \mathrm{C}$

Gambar 11. Kadar Fe dan Ni pada kondisi $\mathrm{T}=300^{\circ} \mathrm{C}$

Pada grafik kondisi suhu $300^{\circ} \mathrm{C}$ berbeda dengan kondisi suhu $250^{\circ} \mathrm{C}$ pada grafik ini memperlihatkan kenaikan kadar FeNi namun pada pengujian ini didapatkan kadar nikel yang cukup kecil dibandingkan dengan kondisi suhu $250^{\circ} \mathrm{C}$.

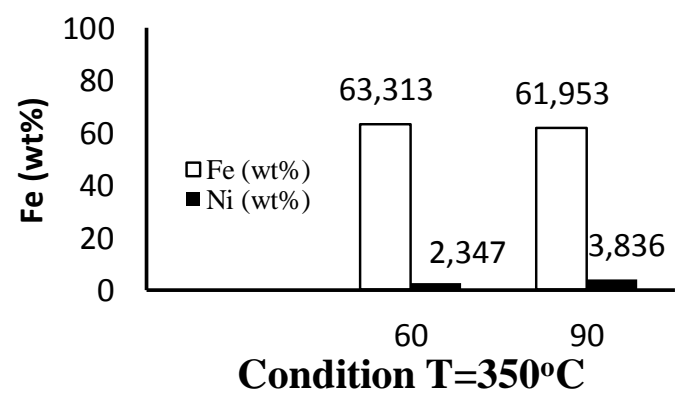

Gambar 12. Kadar Fe dan Ni pada kondisi $\mathrm{T}=350^{\circ} \mathrm{C}$

Pada grafik kondisi $350^{\circ} \mathrm{C}$ terjadi perbedaan dengan kedua grafik di atas dimana pada grafik ini kadar Ni mengalami 
kenaikan dan kadar $\mathrm{Fe}$ mengalami penurunan. Jadi dilihat dari grafik-grafik tersebut variasi suhu dan waktu sangat berpengaruh tehadap kadar $\mathrm{FeNi}$ yang dihasilkan.

Analisis XRF dilakukan untuk mengetahui komposisi yang terkandung pada bijih laterit menggunakan XRF Olympus $\mathrm{X}$ dan Excel untuk analisa hasil XRF. Analisa struktur mikro menggunakan mikroskop optik Nikon.Untuk mengetahui mikrostruktur yang terbentuk pada hasil reduksi, dilakukan pengamatan menggunakan mikroskop optik. Karena ini masih identifikasi awal jadi belum terlihat jelas atau masih sulit untuk membedakan yang mana fasa feronikel dan yang mana fasa lain yang dianggap pengotor. Untuk mengetahui lebih jelas dari fasa-fasa tersebut disarankan untuk melakukan pengujian XRD.

\section{Kesimpulan}

Melalui proses reduksi selektif dengan dua tahap proses panas guna untuk meningkatkan nilai tambah biji nikel laterit ini sangat efektif dari awal biji nikel kadar rendah dengan kandungan nikel 1-2\%, dengan dilakukanya proses pemanasan dari suhu $250{ }^{\circ} \mathrm{C}, 300^{\circ} \mathrm{C}, 350{ }^{\circ} \mathrm{C}$ dengan waktu tahan 60 menit dan 90 menit dengan komposisi biji nikel limonit sebesar 50 gram ditambahkan reduktor grafit sebanyak 0,854 gram dan zat aditif $\mathrm{Na}_{2} \mathrm{SO}_{4}$ sebanyak 5 gram maka didapatkan kandungan nikel yang cukup tinggi yaitu 5-6\% dengan ini maka dapat disimpulkan bahwa proses benefisiasi dengan metode tersebut sangat efektif dan optimal.

Kadar $\mathrm{Fe}$ dalam konsetrat yang diperoleh dari beberapa pengujian yaitu mengalami kenaikan dan penurunan dengan ditambahkanya temperatur dan waktu tahan. Untuk waktu tahan 60 menit didapatkan kadar Fe yang paling tinggi yaitu pada suhu $250{ }^{\circ} \mathrm{C}$ sebesar $67,853 \%$ dan untuk waktu tahan 90 menit kadar $\mathrm{Fe}$ yang paling tinggi yaitu pada suhu $300{ }^{\circ} \mathrm{C}$ sebesar $66,013 \%$. Sedangkan untuk kadar $\mathrm{Ni}$ yang tertinggi yaitu sebesar $6,079 \%$ pada suhu $250{ }^{\circ} \mathrm{C}$ dengan waktu tahan 60 menit. Jadi suhu yang paling optimal dalam penelitian ini yaitu pada suhu $250^{\circ} \mathrm{C}$ dengan waktu tahan 60 menit karena didapatkan kadar nikel yang tinggi.

\section{Ucapan Terimakasih}

Terimakasih untuk Lembaga Penelitian dan Pengabdian kepada Masyarakat (LPPM) Universitas Muhammadiyah Metro dan Balai Penelitian Teknologi Mineral - Lembaga Ilmu Pengetahuan Indonesia (BPTM-LIPI) Tanjung Bintang.

\section{Referensi}

[1] Nurhakim, M. Untung Dwiatmoko, Romla N. H., Adip M, 2011, "Identifikasi Potensi Endapan Bijih Besi Laterit di Bagian Tengah Pulau Sebuku, Provinsi Kalimantan Selatan”. Info Teknik, Vol. 12, No. 2.

[2] Kuck, P. H., 2016, Mineral Commodity Summaries. doi: 10.3133/70140094.

[3] Moskalyk, R. R. dan Alfantazi, A. M., 2002, "Nickel laterite processing and electrowinning practice", Minerals Engineering, 15(8), hal. 593-605. doi: 10.1016/S0892-6875(02)00083-3.

[4] Dalvi, A. D., Bacon, W. G., dan Osborne, R. C., 2004, "The Past and The Future of Nickel Laterites", Proceeding PDAC 2004, International Convention, Trade Show and Investors Exchange (Prospectors and Developers Association of Canada), March 7-10, Toronto.

[5] Pournaderi, S., 2014, "Optimization of FerroNikel Reduction from Nickel Laterite Ores", Thesis. School of Natural and Science, hal. 195.

[6] Kose, S., 2010, "Hydrometallurgical Processing of Lateritical Nickel Ores", Thesis: Metallurgical and Materials Engeneering, hal. 195.

[7] Kyle, J., 2010, "Nickel Laterit Processing Technologies-Where to Next", Murdoch University: Repository. 
[8] Diaz, C. M., Vahed, A., Shi, D., Doyle, C. D., Warner, A. E. M., MacVicar, D. J., 1993, "Low Temperatur Thermal Upgrading of Lateritic Ore", US Patent 5178666 A.

[9] Elliot R., Pickles C. A., Forster J., 2015, "Pyrometallurgical upgrading of nickeliferous laterites: a comparison of thermodynamic and reduction roasting studies", in Conference: Processing of Nickel Ores and Concentrates, Falmouth.

[10] Yang, S., Du, W., Shi, P., Shangguan, J., Liu, S., Zhou, C., Chen, P., Zhan, Q., Fan, H., 2016, "Mechanistic and Kinetic Analysis of Na2SO4Modified Laterite Decomposition by Thermogravimetry Coupled with Mass Spectrometry", Plos One, hal. 121.

[11] Rodrigues, F. M., 2013, "Investigation Into The Thermal Upgrading of Nickeliferous Laterite Ore", Thesis, Queen's University Kingston, Ontario, Canada.

[12] Rao M., Li G., Jiang T., Luo J., Zhang Y., Fan X., 2013, "Carbothermic reduction of nickeliferous laterite ores for nickel pig iron production in China: A review", Journal of the Minerals, Metals \& Materials Society, hal. 1573-1583.

[13] Ilschner B., Grant N., Russell K., 1991, Materials Beneficiation. Springer-Verlag Inc., New York.

[14] Fansuri,H., (2010), Modul Pelatihan Operasional XRF. Laboratorium Energi dan Rekayasa, LPPMS ITS, Surabaya.

[15] Douglas B. Murphy (2001): Dasardasar mikroskop cahaya dan pencitraan elektronik, Wiley-lis, Inc., New York. 